\title{
Label-free impedimetric biosensor for Salmonella Typhimurium detection based on poly [pyrrole-co-3-carboxyl-pyrrole] copolymer supported aptamer
}

E. Sheikhzadeh, M. Chamsaz, Anthony Turner, Edwin Jager and Valerio Beni

Linköping University Post Print

\section{Tweet}

N.B.: When citing this work, cite the original article.

Original Publication:

E. Sheikhzadeh, M. Chamsaz, Anthony Turner, Edwin Jager and Valerio Beni, Label-free impedimetric biosensor for Salmonella Typhimurium detection based on poly [pyrrole-co-3carboxyl-pyrrole] copolymer supported aptamer, 2016, Biosensors \& bioelectronics, (80), 194200.

http://dx.doi.org/10.1016/j.bios.2016.01.057

Copyright: Elsevier

http://www.elsevier.com/

Postprint available at: Linköping University Electronic Press

http://urn.kb.se/resolve?urn=urn:nbn:se:liu:diva-127248 


\section{Label-free impedimetric biosensor for Salmonella Typhimurium detection \\ 2 based on poly [pyrrole-co-3-carboxyl-pyrrole] copolymer supported aptamer.}

3 E. Sheikhzadeh ${ }^{1,2}$, M. Chamsaz ${ }^{2}$, A. P. F.Turner ${ }^{1}$, E. W. H. Jager ${ }^{1}$, V. Beni ${ }^{1 \S^{*}}$

${ }^{1}$ Biosensors \& Bioelectronics Centre, Dept. of Physics, Chemistry and Biology (IFM), Linköping University, Linköping, Sweden

8 Corresponding author:

9 Dr. Valerio Beni Ph.D.

10 e-mail: valerio.beni@acreo.se

12 Current affiliation:

13 §ACREO SWEDISH ICT AB, Box 787, SE-601 17 Norrköping, Sweden

\section{ABSTRACT}

The Gram-negative bacterium, Salmonella Typhimurium (S. Typhimurium) is a food borne

17 pathogen responsible for numerous hospitalisations and deaths all over the world. Conventional

18 detection methods for pathogens are time consuming and labour-intensive. Hence, there is

19 considerable interest in faster and simpler detection methods.

20 Polypyrrole-based polymers, due to their intrinsic chemical and electrical properties, have been 21 demonstrated to be valuable candidates for the fabrication of chemo/biosensors and functional 22 surfaces. Similarly aptamers have been shown to be good alternatives to antibodies in the 23 development of affinity biosensors.

24 In this study, we report on the combination of poly [pyrrole-co-3-carboxyl-pyrrole] copolymer and 25 aptamer for the development of a label-less electrochemical biosensor suitable for the detection of 
26 S. Typhimurium. Impedimetric measurements were facilitated by the effect of the aptamer/target 27 interaction on the intrinsic conjugation of the poly [pyrrole-co-3-carboxyl-pyrrole] copolymer and 28 subsequently on its electrical properties. The aptasensor detected S. Typhimurium in the 29 concentration range $10^{2}-10^{8} \mathrm{CFU} \mathrm{mL}^{-1}$ with high selectivity over other model pathogens and with 30 a limit of quantification (LOQ) of $100 \mathrm{CFU} \mathrm{mL}^{-1}$ and a limit of detection (LOD) of $3 \mathrm{CFU} \mathrm{mL}^{-1}$. 31 The suitability of the aptasensor for real sample detection was demonstrated via recovery studies 32 performed in spiked apple juice samples. We envisage this to be a viable approach for the 33 inexpensive and rapid detection of pathogens in food, and possibly in other environmental samples.

34 Keywords: S. Typhimurium, aptamer, Electrochemical Impedance Spectroscopy, poly [pyrrole35 co-3-carboxyl-pyrrole], label-free detection. 


\section{Introduction}

The Gram-negative bacterium Salmonella is a major food borne pathogen for humans and animals. This pathogen is known as a major factor in gastrointestinal infections and is associated with numerous hospitalisations and deaths all over the world. Salmonella can be found in meat, eggs, milk and beverage. Among the over 2500 serotypes of Salmonella, one of the most common serotype related to human disease is Salmonella enterica serovar typhimurium ( $\underline{\text { S. Typhimurium }}$ ) (Kim et al. 2015; Lee et al. 2015; Ma et al. 2014). Traditional methods of detection of this pathogen are based on the combination of pre-enrichment steps, culturing on Salmonella-Shigella (SS) agar plates, and serological validation of suspicious colonies. Although these approaches can provide reliable results, they are quite time consuming and can take up to 5 days to obtain a result. Due to these drawbacks, the development of new and faster approaches for bacteria detection is a core activity in contemporary microbiology (Lee et al. 2015).

Immunological assays such as ELISA can detect Salmonella at level of $10^{4}-10^{5}$ cells $\mathrm{mL}^{-1}$; and lower detection levels can be achieved by coupling ELISA methods with an enrichment step that usually takes between 16 and 24 h (Alakomi and Saarela 2009; Meng Xu et al. 2015). Polymerase chain reaction (PCR)-based methods have been shown to significantly improve the limit of detection down to $5 \mathrm{CFU}$ (colony forming unit) $\mathrm{mL}^{-1}$, but still these approaches require long and often complicated preparation steps, such as cell lysis and, often, DNA separation. Furthermore these methods do not have the ability to determine the viability of the pathogen at the time of the sampling (Zelada-Guilln et al. 2009; Zourob et al. 2008). Despite significant advances, current Salmonella detection methods are not fast, easy to perform, reliable or sensitive enough (Lee et al. 2015).

Conductive conjugated polymers $(\mathrm{CP})$ are very attractive and versatile materials for the fabrication of functional interfaces and sensing surfaces. They combine the properties of metals and those of conventional polymer and have found application in various areas including extraction methods(Bagheri et al. 2013), fuel cells (Inamuddin et al. 2009), artificial muscles (Jager et al. 2000) and biomedical engineering (Guimard et al. 2007) as well as in chemosensors (Pattananuwat et al. 2015), biosensors (Li et al. 2015) and functional surfaces for cell stimulation(Svennersten et al. 2011), tissue engineering (Svennersten et al. 2011) and bacterial differentiation (Golabi et al. 2016a). 
67 Among CPs, polypyrrole has found widespread application due to properties such as ease of 68 synthesis in different solvents and at room temperature, good chemical stability and high conductivity. Even more interestingly, polypyrrole can be fabricated via electrochemical approaches, giving a high degree of control over thickness, shape, morphology and hydrophobicity (Balint et al. 2014; Janmanee et al. 2013; Kannan et al. 2011; Peng et al. 2007). However, polypyrrole suffers from the absence of functional groups and so copolymerisation of pyrrole with modified monomers has been explored as a possible route to provide polypyrrole films with new 74 functionalities (Melling et al. 2015). Copolymers such as poly[pyrrole-co-4-(3-pyrrolyl] butanoic acid, have been used for the fabrication of DNA hybridisation biosensors (Peng et al. 2005). DNA chips, fabricated using poly[pyrrole-COOH-co-pyrrole-DNA probe] copolymer, were used to detect DNA at levels as low as $10^{-15}$ mole $\mathrm{mL}^{-1}$ (Garnier et al. 2007) and the copolymer, poly[pyrrole-co-3-pyrrolylacrylic acid], has been used for the development of impedimetric genosensors (Peng et al. 2007). Aptamers are short sequences of DNA or RNA that have the ability to bind with high affinity and specificity to their target. They are considered to have several advantages over their corresponding antibodies including small size, ease of synthesis and labelling, low cost of production and the absence of the need for animals to produce them (Zhu et al. 2012).

Electrochemical detection methods are widely used because of their ease of operation, high sensitivity and ready miniaturisation for use in portable device (Zhu et al. 2012). For example, an electrochemical immunosensor based on screen-printed gold electrodes, was developed for the chronoamperometric detection of S. Typhimurium down to 20 cell $\mathrm{mL}^{-1}$ (Salam and Tothill 2009). Zelada-Guillén et al. demonstrated the real-time potentiometric detection of Staphylococcus aureus in pig skin by the use of carbon nanotube/aptamer functionalised electrodes (ZeladaGuillén et al. 2012). Anodic stripping voltammetry was used for electrochemical dual-aptamerbased, sandwich detection of Staphylococcus aureus down to $1 \mathrm{CFU} \mathrm{mL}^{-1}$ (Abbaspour et al. 2015). Finally, a target-induced aptamer displacement strategy has been applied for the detection of $E$. coliO111 via differential pulse voltammetry (Luo et al. 2012).

Label-free electrochemical detection is a very attractive option and has been demonstrated by the use of electrochemical impedance spectroscopy. For example an electrochemical impedance 
was able to detect the pathogen in the concentration range $2.4-2.4 \times 10^{3} \mathrm{CFU} \mathrm{mL}^{-1}$ (Ma et al. 2014). Furthermore, a screen-printed interdigitated microelectrode, in combination with magneticbead sample separation was applied for the rapid detection of E. coli O157:H7 and S. Typhimurium in food samples (Meng Xu et al. 2015). In addition, Labib et al, developed an aptamer-based impedimetric sensor with the ability to detect $S$. enteritidis down to $600 \mathrm{CFU} \mathrm{mL}^{-1}$ in 10 minutes, and to distinguish it from other Salmonella species, including S. typhimurium and S. choleraesuis (Labib et al. 2012a). The same authors developed an impedimetric sensor via the self-assembly of thiolated aptamer onto a gold nanoparticle-modified screen-printed electrode. The tunable specificity of the aptamers, allowed live and killed bacteria be distinguished (Labib et al. 2012b) .

Unfortunately however, all the label-free electrochemical approaches described above required the presence of a redox probe, more often ferro/ferricyanide, in the measuring solution. In the study presented herein, we report on the use of the poly[pyrrole-co-3-carboxyl-pyrrole] copolymeraptamer bioconjugated for the development of a label-free electrochemical biosensor for the detection of S. Typhimurium based on the intrinsic variation of the electrical properties of the polymeric surface, without the need for the addition of redox probes. The potentiality of the proposed aptasensor was demonstrated via calibration, selectivity and recovery experiments, which demonstarted its specificity, sensitivity and applicability for the detection of $S$. Typhimurium in a food sample (apple juice).

\section{Experimental}

\subsection{Materials}

Analytical grade reagents without further purification, except for pyrrole monomer (vacuum distilled prior to use), were used in this work.

Pyrrole-3-carboxylic acid (Py-COOH) was purchased from Fluoro chem (Hadfield United Kingdom) and lithium perchlorate $\left(\mathrm{LiClO}_{4}\right)$ from Acros. N-hydroxysuccinimide (NHS), N-(3-dimethylaminopropyl)-N'-ethylcarbodiimide hydrochloride (EDC) and Pyrrole (Py) were obtained from Sigma-Aldrich (Stockholm, Sweden). PBS (pH 7.4) tablets were supplied by Medicago AB (Uppsala, Sweden).

The six bacterial strains used in this study were: Escherichia Coli (CCUG 3274, CCUG53375, and CCUG10979), Entrobacter aerogenes and Citrobacter freundii) and S. Typhimurium. The three E. 
Coli strains were acquired from the Culture Collection, University of Gothenburg, Sweden, the other strains were provided, in kind, by Linköping University Hospital. Aptamer with $5^{\prime}-\mathrm{NH}_{2}$-ttt ggt cet tgt ctt atg tcc aga atg cga gga aag tct ata gca gag gag atg tgt gaa ccg agt aaa $\mathrm{ttt}$ ctc cta ctg gga tag gtg gat tat-3' sequence ( $\mathrm{N} 45$ in the original manuscript) was obtained from a previous work reported by Joshi A et al. (Joshi et al. 2009). The synthetic aptamer was purchased lyophilised from biomers.net (Germany). On arrival, the aptamer was reconstituted to a $100 \mu \mathrm{M}$ stock solution with filtered (0.2 Micron filter) Milli-Q water, divided in small aliquots and stored at $-20{ }^{\circ} \mathrm{C}$ until use.

All solutions were prepared in high purity water obtained from a Milli-Q RG system (Stockholm, Sweden).

\subsection{Apparatus}

An Ivium Stat.XR electrochemical analyser coupled with dedicated software (Ivium, Eindhoven, Netherlands) was used for electrochemical measurements, film deposition and cleaning of the gold surface. Attenuated total reflectance (ATR-FTIR) measurements were done with a PIKE MIRacle ATR accessory with a diamond prism in a Vertex 70 spectrometer (Bruker) using a DTGS detector; all measurements were performed at room temperature under continuous purging of $\mathrm{N}_{2}$. IR spectra were obtained at $4 \mathrm{~cm}^{-1}$ resolution and 32 scans between 4000 and $800 \mathrm{~cm}^{-1}$. The Scanning Electron Microscopy (SEM) micrographs were taken using a Leo 1550 Gemini SEM operating at $6.0 \mathrm{keV}$. A Shimadzu UV-1601 PC spectrophotometer was used to obtain the concentration of cultured bacteria $(600 \mathrm{~nm})$. Contact angle measurements were carried out using a CAM 200 optical contact angle meter (KSV Instrument, Helsinki, Finland).

\subsection{Preparation of the film}

Gold disk electrodes (internal diameter $2 \mathrm{~mm}$ from CHI Instruments), USA) were polished on polishing pad micro clothes with 1.0, 0.3 and $0.05 \mu \mathrm{m}$ alumina powder (CHI Instruments, USA) to a mirror finish and then cleaned in a water ultrasonic bath. After the mechanical cleaning, the surface was immersed for $60 \mathrm{~s}$ in cold piranha solution $\left(3: 1 \mathrm{H}_{2} \mathrm{SO}_{4} / \mathrm{H}_{2} \mathrm{O}_{2}\right)$ followed by an electrochemical activation step in $\mathrm{H}_{2} \mathrm{SO}_{4}(0.5 \mathrm{M})$ solution by cyclic voltammetry (25 cycles).

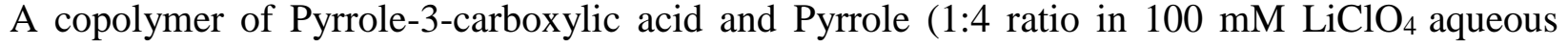
solution) was synthesised using a potentiostatic (constant potential) method at $0.7 \mathrm{~V}$ (vs $\mathrm{Ag} / \mathrm{AgCl}$, 
$\mathrm{KCl} 3 \mathrm{M}$ reference electrode) until the consumed charge reached $5 \mathrm{mC} \mathrm{cm}^{-2}$. The prepared film was washed with deionised water and stored at $4{ }^{\circ} \mathrm{C}$ until use.

For SEM and FT-IR images, the same procedure was applied on $5 \times 10 \mathrm{~mm}$ Au chips produced by sputtering a $2000 \AA$ Au film onto a Ti coated (100 ̊̊) Si wafer.

\subsection{Immobilisation of aptamer onto polymeric film}

The presence of the carboxylic group in the poly[pyrrole-co-3-carboxyl-pyrrole] copolymer films allowed the covalent immobilisation of the aptamer (Chei et al. 2008; Tlili et al. 2005). Functionalisation of the copolymer with aptamers was carried out by immersing the film in $40 \mu \mathrm{L}$ aqueous solution containing $50 \mathrm{mM}$ NHS and $200 \mathrm{mM}$ EDC for $30 \mathrm{~min}$, in order to activate the carboxylic group present,; this was, followed by incubation of the activated film with $20 \mu \mathrm{L}$ of a $2 \mu \mathrm{M}$ aqueous solution of the amino-functionalised aptamer for $60 \mathrm{~min}$.

\subsection{Preparation of bacterial solution}

The six bacterial strains were cultured separately in Tryptic Soy Broth (TSB) for $18 \mathrm{~h}$, at $37{ }^{\circ} \mathrm{C}$ under gentle $(170 \mathrm{rpm})$ shaking. The overnight cultured bacterial cells were then collected by centrifugation (5 min at 5000g), the supernatant discarded and the pellet resuspended in sterile phosphate buffered saline (PBS) solution (pH 7.4). Following three cycles of washing (accordingly to the procedure described above) the bacterial solutions were diluted to $10^{8} \mathrm{CFU} \mathrm{mL}^{-1}$ (concentration calculated according to Mc Farland turbidity standards ); these solutions were used as the working stock bacterial solutions. Serial dilutions $\left(10^{2}-10^{8} \mathrm{CFU} / \mathrm{mL}\right)$ of standard stock solutions were prepared with $\mathrm{LiClO}_{4} 100 \mathrm{mM}$ for measurement.

\subsection{Impedance measurement}

The impedance measurements were recorded from $10 \mathrm{kHz}$ to $0.5 \mathrm{~Hz}$, at amplitude of $5 \mathrm{mV}$, in 100 $\mathrm{mM} \mathrm{LiClO}_{4}$ solution without any redox probe. All measurements were performed at a bias potential of $0 \mathrm{mV}$ vs the $\mathrm{OCP}$ (open circuit potential) of the film.

Measurement in the presence of the redox probing molecule ( $5 \mathrm{mM}$ Ferro/Ferri equimolar solution) were also attempted; this resulted to be less reproducible and noisier (data not shown) making in this way favorable the measurements in $100 \mathrm{mM} \mathrm{LiClO}_{4}$ solution alone. 


\subsection{Bacteria measurements}

Detection of bacteria was performed accordingly to the following protocol: aptasensor were incubated for $45 \mathrm{~min}$ in the $\mathrm{LiClO}_{4} 100 \mathrm{mM}$ solution containing the bacteria or in the 1 to 100 diluted apple juice. Following a 15 min wash in $\mathrm{LiClO}_{4} 100 \mathrm{mM}$ the EIS spectra were recorded accordingly to protocol described in section 2.6. Calibration curve were performed by exposing the aptasensor to increasing concentrations from $10^{2}$ to $10^{8} \mathrm{CFU} \mathrm{mL}^{-1}$ of S. Typhimurium. For each concentration measurements were performed following the protocol described above. Following recording the EIS spectra the aptasensors were put in contact with the solution containing the following higher concentration to be investigated.

\section{Please insert Scheme 1 here}

\section{RESULTS AND DISCUSSION}

\subsection{Characterisation of Copolymer}

\subsubsection{Scanning electron microscopy (SEM)}

Fig.1 shows the SEM images (low and high resolution) of a polypyrrole (PPy) (Fig. 1A and Fig. 1B) and poly[pyrrole-co-3-carboxyl-pyrrole] copolymer (Fig. 1C and Fig. 1D) films synthesised according to the protocol described in the Experimental Section. Clearly the two surfaces showed different morphology; poly[pyrrole-co-3-carboxyl-pyrrole] copolymer film presented a smoother structure when compared with the PPy(Guimard et al. 2007). The PPy film was characterised by the well-known globular and compact structure of PPy The smoother surfaces recorded in the case of the poly[pyrrole-co-3-carboxyl-pyrrole] copolymer film could be due to the reduced polymerisation speed (ca. 2.5 times slower than those of PPy) (Xu et al., 2005; Street et al., 1983; Golabi et al. 2016b) and to the presence of the $\mathrm{COOH}$ that introduced into the copolymer chain sterical and electrostatic hindrances (Korri-Youssoufi and Yassar 2001) resulting in a more planar, more flat linear chain.

\subsubsection{ATR-FTIR spectroscopic measurements}


220 Copolymer formation was further confirmed by ATR-FTIR spectroscopic measurements (Fig. 1E).

221 The poly[pyrrole-co-3-carboxyl-pyrrole] copolymer (blue line) showed a peak at $1680 \mathrm{~cm}^{-1}$, which

222 is associated with the $\mathrm{C}=\mathrm{O}$ stretching mode of carboxylic groups (Peng et al. 2005) and which is

223 clearly absent in the PPy film (red line). Furthermore a shift to higher frequencies of FT-IR

224 spectrum of poly[pyrrole-co-3-carboxyl-pyrrole]copolymer was recorded; this was an indication

225 of the reduced rotational freedom in the polymer probably due to the changes in the polymer

226 backbone associated with the presence of $\mathrm{COOH}$ in it.

227

228

\subsubsection{Cyclic voltammetry measurements}

229

Electrochemical characterisation of the prepared films was performed using cyclic voltammetric and impedimetric measurements. Cyclic voltammograms of the prepared films were recorded in $\mathrm{LiClO}_{4} 100 \mathrm{mM}$ solution; these experiments allowed a deeper understanding of the redox properties of the films (Fig 2A). The poly[pyrrole-co-3-carboxyl-pyrrole] copolymer showed two distinct couples of redox peaks $(-0.5 /-0.6 \mathrm{mV}$ and $-0.15 /-0.16 \mathrm{mV})$ attributed, respectively, to the pyrrole- $\mathrm{COOH}$ unit and to the pyrrole monomer oxidation/reduction (Chei W. et al 2008). On the other hand, when cyclic voltammetric experiments were recorded for the PPy film, only a pair of redox peaks at $-0.15 \mathrm{~V}$ and $-0.16 \mathrm{~V}$ was recorded. Another significant difference was that the poly[pyrrole-co-3-carboxyl-pyrrole] copolymer showed a quasi-reversible behavior, while the PPy demonstrated reversible behavior; these changes in redox properties could be associated with the reduced conductivity of the film, loss in polymer chain conjugation (Garnier et al., 2007), when the monomer with the $\mathrm{COOH}$ group was incorporated in the film (Chei W. et al 2008). This difference recorded in the voltammetric spectra confirms the successful electrodeposition of the poly[pyrrole-co-3-carboxyl-pyrrole] copolymer and that this has a block-polymer form (KorriYoussoufi and Yassar 2001).

\section{Please insert Fig2 here}

\subsubsection{Contact angle measurement}

248 Contact angle measurements were used to study the wettability properties of the surface. The 249 poly[pyrrole-co-3-carboxyl-pyrrole] copolymer showed a reduced contact angle when compared 
250 to the PPy film (Table 1S). This reduction in contact angle is a clear indication of the increased

251 hydrophilic character of the copolymer. This increased hydrophilicity was ascribed to the presence

252 of the carboxylic acid groups and to their ability to form hydrogen bonds with the water .(Truong 253 et al. 2011)

\subsubsection{Impedance measurement}

256 Impedance measurements showed a reduced intrinsic conductivity (increase in resistance) of the

257 poly[pyrrole-co-3-carboxyl-pyrrole] copolymer when compared to the PPy film (Fig 1S). The

258 presence of the $\mathrm{COOH}$ groups in the copolymer chain is expected to introduce a sterical and 259 electrostatic hindrance that is expected to affect the conjugation in the polymeric film. Alteration 260 of the $\pi-\pi$ conjugation in PPy films has been shown to have a significant effect on the film 261 conductivity (Garnier et al., 2007).

\subsection{Aptamer immobilisation}

264 The Au electrodes modified with poly[pyrrole-co-3-carboxyl-pyrrole] copolymer film were used to develop aptasensors via covalent immobilisation of the aptamer onto the surface using EDC/NHS chemistry (methods section). In this step high concentration of amino modified aptamer

$267(2 \mu \mathrm{M})$ was used with the aim of saturating with aptamer the copolymer. Immobilisation of aptamer onto the surface was confirmed by contact angle measurement (Table 1S) and electrochemical impedance measurements (Fig 2B). The presence of phosphate groups in the aptamer structure was considered, responsible for the increased hydrophilicity of the poly[pyrroleco-3-carboxyl-pyrrole] copolymer-aptamer surface, which was clearly highlighted by the reduced

272 contact angle value (Table 1S). This result was confirmed by EIS measurement (Fig 2B). A general

273 circuit was utilised to model the impedance spectrum (inset Fig 2B). In the proposed circuit,

274 previously described by Tlili et al (Tlili et al., 2005), Rs represents the solution resistance, Rct is 275 the charge transfer resistance at the copolymer-aptamer/electrolyte interface, and CPE is the 276 constant phase element accounting for the charge capacitance at the copolymer-

277 aptamer/electrolyte interface. The model was shown to fit adequately the response obtained for the 278 different surfaces investigated including poly[pyrrole-co-3-carboxyl-pyrrole] copolymer and 279 poly[pyrrole-co-3-carboxyl-pyrrole] copolymer-aptamer bioconjugate and for the sensor response 
upon detection of S. Typhimurium at the different concentration investigated. This could be clearly seen from Fig $2 \mathrm{~S}$ where example of the fitting results are presented.

The value of Rct changed significantly following aptamer immobilisation, passing from ca. $78 \Omega$ for the poly[pyrrole-co-3-carboxyl-pyrrole] copolymer, to ca. $1118 \Omega$ for the poly poly[pyrroleco-3-carboxyl-pyrrole] copolymer-aptamer bioconjugated film. This result was consistent with previous report where the aptamer attachment was associated with an increase in the resistance of the polymer (Zhu et al. 2012).

\subsection{Detection of bacteria}

Different concentration of bacteria solutions $\left(10^{2}-10^{8} \mathrm{CFU} \mathrm{mL}^{-1}\right)$ were prepared by dilution of bacterial stock solutions in $\mathrm{LiClO}_{4} 100 \mathrm{mM}$. The choice of $\mathrm{LiClO}_{4}$ was dictated by the fact that incubation (45 min) in PBS (the buffer in which the aptamer was selected) (Joshi et al., 2009) resulted in a significant alteration of the conductivity properties of the poly[pyrrole-co-3-carboxylpyrrole] copolymer-aptamer film, as clearly indicated by the EIS measurements reported in the Supporting Information (Fig 3S).

The suitability of $\mathrm{LiClO}_{4}$ solution for bacteria detection was investigated by comparing the EIS results before and after the incubation of poly[pyrrole-co-3-carboxyl-pyrrole] copolymer-aptamerfilms with $100 \mathrm{mM} \mathrm{LiClO}_{4}$ solution with $\left(10^{6} \mathrm{CFU} \mathrm{mL}^{-1}\right)$ and without $S$. Typhimurium As can be seen from Fig 4S, when bacteria were absent, there was no significant change in the impedimetric response. On the other hand, when bacteria were present, a clear increase in the impedance response was recorded (Fig 2B). Interaction between the aptamer and bacteria is expected to induce significant changes in the poly[pyrrole-co-3-carboxyl-pyrrole] copolymer-aptamer-films electrical properties by altering significantly the environment in close proximity with polymeric chains (Peng H., et al., 2009; Tlili et al. 2005). Several phenomena have been shown to alter the intrinsic conductivity properties of CPs including: (i) alteration of the $\pi-\pi$ conjugation (Garnier, F. et al., 2007) due to the steric hindrance generated by the introduction, following biorecognition, in the polymer body of the bulky bioorganism, (ii) changes in the interfacial double layer due to the charge properties of the pathogens (Zelada-Guilln G. et al., 2009) and (iii) reduction in the mobility 
of the dopant $\left(\mathrm{ClO}_{4}^{-}\right)$due to the electrostatic repulsion induced by the pathogens (Thompson L.A. et al., 2003).

In order to confirm the role of the aptamer in the performance of the biosensor, two control experiments were performed. In the first experiment, poly[pyrrole-co-3-carboxyl-pyrrole] copolymer film without immobilised aptamer were incubated with $\left(10^{4} \mathrm{CFU} \mathrm{mL}{ }^{-1}\right)$ bacterial solution. In the second experiment, a biosensor modified with an E.Coli-specific aptamer (Bruno 2014), was incubated with the same concentration of bacteria. The results of these control experiments (Fig 5S and Fig 6S, respectively) clearly showed limited response, probably due to physical absorption of bacteria onto the polymeric surface, when compared to those recorded with the proposed S. Typhimurium aptasensor.

\subsection{Optimisation of incubation time for $S$. Typhimurium detection}

Prior to evaluating the analytical performance, in terms of response/concentration and selectivity, the influence of the incubation time on the aptasensor response was evaluated. In order to explore this, aptasensors were incubated with bacterial solution $\left(10^{6} \mathrm{CFU} \mathrm{mL}{ }^{-1}\right)$ for different incubation times (Fig 7S). In order to minimise the variability that can be recorded between different aptasensor the relative variation of Rct ( $\Delta \operatorname{Rct} / \operatorname{Rct} 0)$ was used as analytical response (Nasef et al., 2010). This value was calculated as follows:

$\Delta \operatorname{Rct} / \operatorname{Rct} 0=\left(\operatorname{Rct}_{\text {after }}-\operatorname{Rct} 0\right) / \operatorname{Rct} 0 \quad($ eq. 1$)$

where Rct $_{\text {after }}$ is the value of Rct after recognition of the pathogen and Rct0 is the value recorded for the poly[pyrrole-co-3-carboxyl-pyrrole] copolymer-aptamer-films before the incubation with the solution containing the pathogen.

As it can be seen from Fig 8S, the analytical response increased until 45 min when it started to level off. A longer incubation time (60 min) did not result in a significant increase in the response; subsequently 45 min was selected as incubation time for the following experiments.

\subsection{S. Typhimurium calibration curve}

Calibration curves were built following the protocol described in the material and method section (section 2-7). Typical aptasensor responses are illustrated in Fig 3A and a calibration plot is presented in Fig 3B. The relative resistance was shown to increase linearly $(y=0.1566 x-$ 
341 0.0382equation with $\mathrm{R}^{2}=0.99$ ) with the logarithm of the S. Typhimurium concentration within the 342 investigated concentration interval (range of $10^{2}-10^{8} \mathrm{CFU} \mathrm{mL}^{-1}$ ) with a LOQ of $10^{2} \mathrm{CFU} \mathrm{mL}^{-1}$ 343 and a LOD (3 time the standard detection of the blank experiment: incubation in the absence of $S$. 344 Typhimurium) of $3 \mathrm{CFU} \mathrm{mL}^{-1}$. Error bars in the calibration indicate the reproducibility (3 345 measurements), over 2 days, performed using 3 different aptasensors.

346 Reproducibility of the aptasensor was calculated over the full range of concentration; this resulted 347 in an average RSD of 5.2\% ( $\mathrm{n}=3$ for each of the 7 concentrations used in this calculation and listed 348 in Table 2S).

\subsection{Selectivity of the aptasensor}

351 Three different strains of E. Coli, Enterobacter and Citrobacter were utilised to investigate the specificity of the aptasensor. Solutions containing $10^{6} \mathrm{CFU} \mathrm{mL}^{-1}$ of each bacterium were incubated with the aptasensor for $45 \mathrm{~min}$. As it can be seen from Fig 3C, the relative resistances (calculated accordingly to eq. 1) for the five investigated bacteria strains are much lower than those recorded for the S. Typhimurium, confirming the specificity of the aptasensor. Interestingly is the fact that for interfering strain resulted in a loss of Rct; the reason for these results are not clear but they might reside in the intrinsic charge and morphological properties of the different pathogens.

\section{Please insert Fig 3 here}

\subsection{Real sample measurement}

Real sample measurements were carried out in spiked $\left(10^{2}\right.$ and $\left.10^{6} \mathrm{CFU} \mathrm{mL}^{-1}\right)$ filtered and diluted apple juice. Dilution of the apple juice (1 to 100) was performed using $\mathrm{LiClO}_{4} 100 \mathrm{mM}$ as dilution media. The results of the recovery studies are summarised in Table 1. Concentrations of bacteria eq. 1) variation in the calibration curve of Fig. 3B. Clearly the aptasensor worked in diluted spiked real samples. Reproducibility of the detection was calculated for both spiked concentration $(n=3)$; this resulted in an average RSD of $11 \%$.

\section{Please insert Table 1 here}




\section{Conclusions}

372 In this study the successful fabrication of the poly [pyrrole-co-3-carboxyl-pyrrole] copolymer and

373 its conjugation with a S. Typhimurium specific aptamer was achieved. Chemical (FT-IR) physical

374 (electrochemical and contact angle) characterisations were used to confirm the synthesis of the 375 designed bioconjugate film. The use of the poly [pyrrole-co-3-carboxyl-pyrrole] copolymer376 aptamer bioconjugate as sensing surface in electrochemical impedance label-free aptasensor was 377 also investigated. The proposed method sensing surface was demonstrated to allow sensitive 378 detection of S. Typhimurium in a fast and sensitive way by taking advantage of the changes, 379 following aptamer pathogen interaction, in the electrical properties of the poly [pyrrole-co-3380 carboxyl-pyrrole] copolymer without the need of the addition of any reporting redox probe. This 381 significantly simplifies the assay opening in this way new possibility for fast in situ screening of 382 environmental and food products. The developed label-free aptasensors was shown to respond 383 linearly over the $S$. Typhimurium concentration range $10^{2}-10^{8} \mathrm{CFU} \mathrm{mL}^{-1}$ with a LOQ of $10^{2} \mathrm{CFU}$ $384 \mathrm{~mL}^{-1}$ and a LOD of $3 \mathrm{CFU} \mathrm{mL}{ }^{-1}$. The aptasensor was also shown to be highly selective for $S$. 385 Typhimurium when compared to the detection of other possible model interfering strains (E. coli 386375 , E.coli 797, E.coli 3274, Enterobacter, Citrobacter). Finally the aptasensor was demonstrated 387 to allow the fast (45 min) label-free detection of S. Typhimurium in spiked apple juice. Despite 388 further work on the stabilisation of the sensor surface will be required, the authors envisage this as 389 a viable approach for inexpensive, simple and rapid detection of pathogens in food and possibly 390 environmental samples.

Acknowledgements

393 The authors are thankful to Mr.Mohsen Golabi for his kind help with the bacterial culturing and 394 experiments and contact angle measurement. ES would like to acknowledge the Ministry of 395 Science Research and Technology of Iran and Research Council of Ferdowsi University of 396 Mashhad (Research project no. 3/29828) to support her research exchange to Linköping 397 University. AT, VB and EJ would like to thank Linköping University, Vetenskapsrådet 398 (Pathoscreen project; Swedish Research Link; ref.-ID: D0675001) and the Swedish Research 399 Council (contract nr VR-2014-3079) for financial support. 


\section{References}

Abbaspour, A., Norouz-Sarvestani, F., Noori, A., Soltani, N., 2015. Biosensors and Bioelectronics 68, 149-

403155.

404 Alakomi, H.L., Saarela, M., 2009. Quality Assurance and Safety of Crops \&Foods 1, 142-152.

405 Bagheri, H., Ayazi, Z., Naderi, M., 2013. Analytica Chimica Acta 767, 1-13.

406 Balint, R., Cassidy, N., J., Cartmell, S., H, , 2014. Acta Biomaterialia 10, 2341-2353.

407 Garnier, F., Bouabdallaoui, B., Srivastava, P., Mandrand, B., Chaix, C., 2007. Sensors and Actuators B 123 408 13-20.

409 Bruno, J.G., 2014, Pathogens 3(2), 341-355.

410 Chei, W., Lu, Z., Li C.M., 2008. Analytical Chemistry 80, 8485-8492.

411 Golabi, M., Turner, A.P.F., Jager, E.W.H., 2016a. Sensors and Actuators B: Chemical 222, 839-848.

412 Golabi, M., Turner, A.P.F., Jager, E.W.H., 2016b. Macromolecular Chemistry and Physics, accepted.

413 Guimard, N., K., Gomez, N., Schmidt, C., E,, 2007. Progress in pollymer Science 32, 876-921.

414 Jager, E., W. H, Smela, E., Inganäs, O., 2000. Science 290 1540-1545(5496), 1540-1545.

415 Janmanee, R., Baba, A., Phanichphant, S., Sriwichai, S., Shinbo, K., Kato, K., Kaneko, F., 2013. Molecular 416 Crystals and Liquid Crystals 580(1), 29-34.

417 Joshi, A., Janagama, H., Dwivedi, H.P., Senthil Kumar, T.M.A., Jaykus, L.-A., Schefers, J., Sreevatsan, S., 418 2009. Molecular and Cellular Probes 23, 20-28.

419 Kannan, B., David E. Williams, Marsilea A. Booth, Travas-Sejdic, J., 2011. Analytical Chemistry 83, 34154203421.

421 Kim, G., Moon, J., Moh, C., Lim, J., 2015. Biosensors and Bioelectronics 67, 243-247.

422 Korri-Youssoufi, H., Yassar, A., 2001. Biomacromolecules 2, 58-64.

423 Labib, M., Zamay, A. S, Kolovskaya, O. S., Reshetneva, I. T., Zamay, G. S., Kibbee, R. J., Sattar, S. A., 424 Zamay, T. N., Berezovski, M.V., 2012a. Analytical Chemistry 84(19), 8114-8117. 
425 Labib, M., Zamay, A., Kolovskaya, O.S., Reshetneva, I. T., Zamay, G. S., Kibbee, R., Sattar, S. A., Zamay, 426 T. N., Berezovski, M., V., 2012b. Analytical Chemistry 84, 8966-8969.

427 Lee, K., Runyon, M., Herrman, T.J., Phillips, R., Hsieh, J., 2015. Food Control 47, 26 24-276.

428 Li, L., Wang, Y., Pan, L., Shi, Y., Cheng, W., Shi, Y., Yu, G., 2015. Nano Letters 15(2), 1146-1151.

429 Luo, C., Lei , Y., Yan, L., Yu, T., Li, Q., Zhang, D., Ding, S., Ju, H., 2012. Electroanalysis 24(5), 11864301191.

431 Ma, J., Jiang, y., Jia, F., Yu, Y., Chen, J., Wang, Z., 2014. Journal of Microbiological Methods 98, 94-98.

432 Melling, D., Wilsona, S., A, , Jager, E.W.H., 2015. RSC Advances 5(10), 84153-84163

433 Nasef, H., Beni, V., Ozalp, V.C., O'Sullivan, C.K., 2010. Anal Bioanal Chem 396, 2565-2574.

434 Pattananuwat, P., Tagaya, M., Kobayashi, T., 2015. Sensors and Actuators B: Chemical 209, 186-193.

435 Peng, H., Soeller, C., Vigar, N., Kilmartin, P. A., Cannell, M. B., Bowmaker, G. A., Cooney, R. P., Travas436 Sejdic, J., 2005. Biosensors and Bioelectronics 20, 1821-1828.

437 Peng, H., Soeller, C., Vigar, N., A,, Caprio, V., Travas-Sejdic, J., 2007. Biosensors and Bioelectronics 22, $438 \quad 1867-1883$.

439 Peng, H., Zhang, L.J., Soeller, C., Travas-Sejdic, J., 2009, Biomaterials 30, 2132-2148.

440 Salam, F., Tothill, I., E., 2009. Biosensors and Bioelectronics 24, 2630-2636.

441 Shin, K. M., Kim, S., I., Insuk So, Kim, S., J,, 2009. Electrochimica Acta 54 3979-3983.

442 Street, G.B., Clarke, T.C., Geiss, R.H., Lee, V. Y., Nazzal, A. I., Pfluger, P., Scott, J. C., 1983, Journal de 443 Physique 44-C3 599.

444 Svennersten, K., Berggren, M., Dahlforsa, A., Jager, E., W. H, 2011. Lab on Chip 11(19), 3287-3293.

445 Thompson, L.A., Kowalik, J., Josowicz, M., Janata, J., 2003. J. Am. Chem. Soc. 125, 324-325.

446 Tlili, C., Korri-Youssoufi, H., Ponsonnet, L., Martelet, C., Jaffrezic-Renault, N., J., 2005. Talanta 68, 131447137.

448 Truong, L.T.N., Chikae, M., Ukita, Y., Takamura, Y., 2011. Talanta 85, 2576- 2580. 
449 Wallace, G. G., Teasdale, P., R., Spinks, G., M., Kane-Maguire, L., A. P., 1997. Conductive Electroactive 450 Polymers: Intelligent Polymer Systems, First Edition.

451 Xu, L.B., Chen, W., Mulchandani, A., Yan, Y.S., 2005. Angew. Chem. Int . 44, 6009 -6012.

452 Xu, M., Wang, R., Li, Y., 2015. Talanta 148, 200-208.

453 Zelada-Guillén, G.A., Sebastián-Avila, J., L,, Blondeau, P., Riu, J., Xavier, R., F., 2012. Biosensors and 454 Bioelectronics 31, 226-232.

455 Zelada-Guilln, G., A,, Riu, J., Duzgun, A., Rius, F.X., 2009. Angewandte Chemie 48, 7334-7337.

456 Zhu, Y., Chandra, P., Song, K.-M., Ban, C., Shim, Y. B., 2012. Biosensors and Bioelectronics 36, $29-34$.

457 Zourob, M., Elwary, S., Turner, A., 2008. Principal of Bacterial Detection,Biosensors, Recognition 458 Receptorsand Microsystems. Springer. 
462

463

464

465

466

467

468

469

470

471

472

473

474

475

476

477

478

479

480

481

482

483

484

485

4

\section{SCHEME, TABLES AND FIGURE CAPTIONS}

Scheme1. Pictorial representation of the proposed approach for aptsensor fabrication.

Table 1: Summary of recovery studies in 1:100 diluted, in $\mathrm{LiClO}_{4} 100 \mathrm{mM}$, apple juice.

Fig 1.SEM image (low and high resolution) of PPy (A and B) and [pyrrole -co- 3-carboxyl pyrrole] copolymer (C and D) deposited onto Silicon based Au film. FT-IR spectrum of (E) [pyrrole -co- 3-carboxyl -pyrrole] copolymer (blue line) and PPy (red line) films.

Fig 2. (A) Cyclic voltammogram of [pyrrole -co- 3-carboxyl -pyrrole] copolymer (red line) and PPy (blue line) in $\mathrm{LiClO}_{4} 100 \mathrm{mM}$ at $50 \mathrm{mVs}^{-1}$. (B) EIS measurements of [pyrrole -co- 3-carboxyl -pyrrole] copolymer film before (red line) and after (blue line) attachment of aptamer and after incubation with $10^{6} \mathrm{CFU} \mathrm{mL} \mathrm{m}^{-1}$ solution of S. Typhimurium (green line) (measurement solution $\left.\mathrm{LiClO}_{4} 100 \mathrm{mM}\right)$. The impedance spectra were recorded from $10 \mathrm{kHz}$ to $0.5 \mathrm{~Hz}$, at $0 \mathrm{mV}$ vs $(\mathrm{OCP})$, amplitude of $5 \mathrm{mV}$ in $\mathrm{LiClO}_{4} 100 \mathrm{mM}$ solution.

75 Fig 3. (A) Impedance measurement for different concentrations $\left(10^{2}-10^{8} \mathrm{CFU} \mathrm{mL}{ }^{-1}\right)$ of $S$. Typhimurium; (B) Calibration curve obtained by fitting the results from 3 consecutive calibration curves. (C) Selectivity evaluation of the aptasensor over the detection of six model pathogens $3 E$. Coli strains, Enterobacter and Citrobacter $\left(10^{6} \mathrm{CFU} \mathrm{mL}^{-1}\right)$ Measurement and capture solution:

$79 \mathrm{LiClO}_{4} 100 \mathrm{mM}$. Error bars (Fig. 3B and Fig. 3C) were obtained by calculating the SD of 3 80 measurements performed each with a different aptasensors. The impedance spectra were recorded 81 from $10 \mathrm{kHz}$ to $0.5 \mathrm{~Hz}$, at $0 \mathrm{mV}$ vs (OCP), amplitude of $5 \mathrm{mV}$ in $\mathrm{LiClO}_{4} 100 \mathrm{mM}$ solution. 


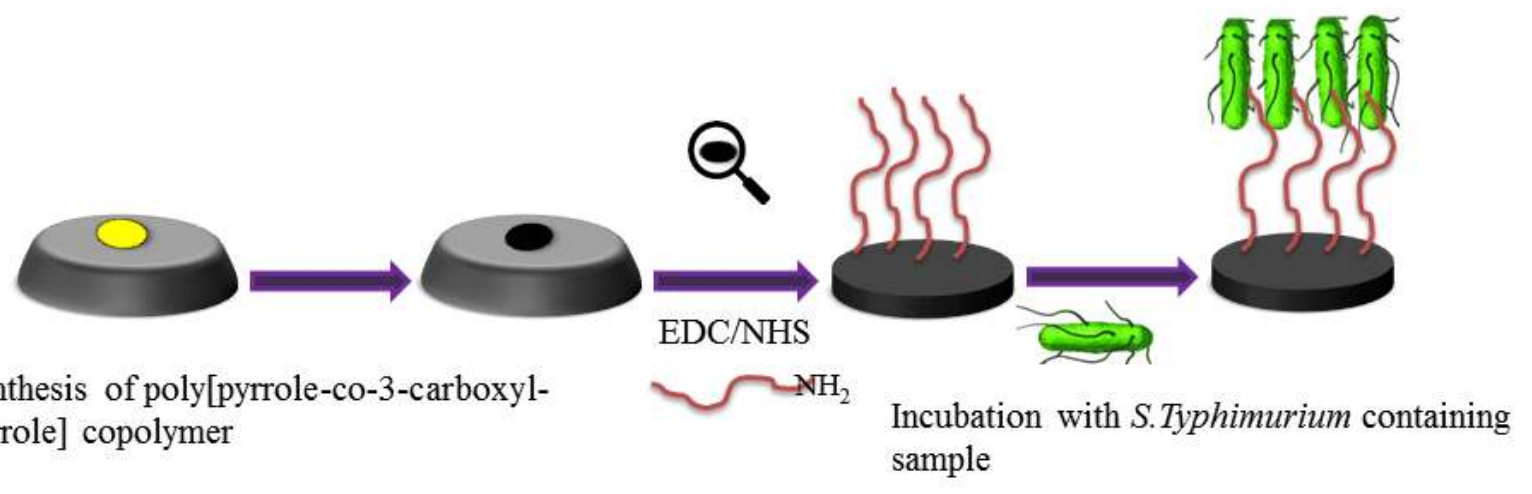


497

498

\begin{tabular}{|c|c|}
\hline $\begin{array}{c}\text { Nominal } \\
\text { Concentration } \\
\text { CFU } \text { mL }^{-1}\end{array}$ & $\begin{array}{c}\text { Experimentally obtained } \\
\text { Concentration } \\
\text { CFU } \mathbf{~ m L}^{-1}\end{array}$ \\
\hline $10^{2}$ & $1.4 \times 10^{2}$ \\
\hline $10^{6}$ & $4.1 \times 10^{6}$ \\
\hline
\end{tabular}

503

504

Table 1

505 

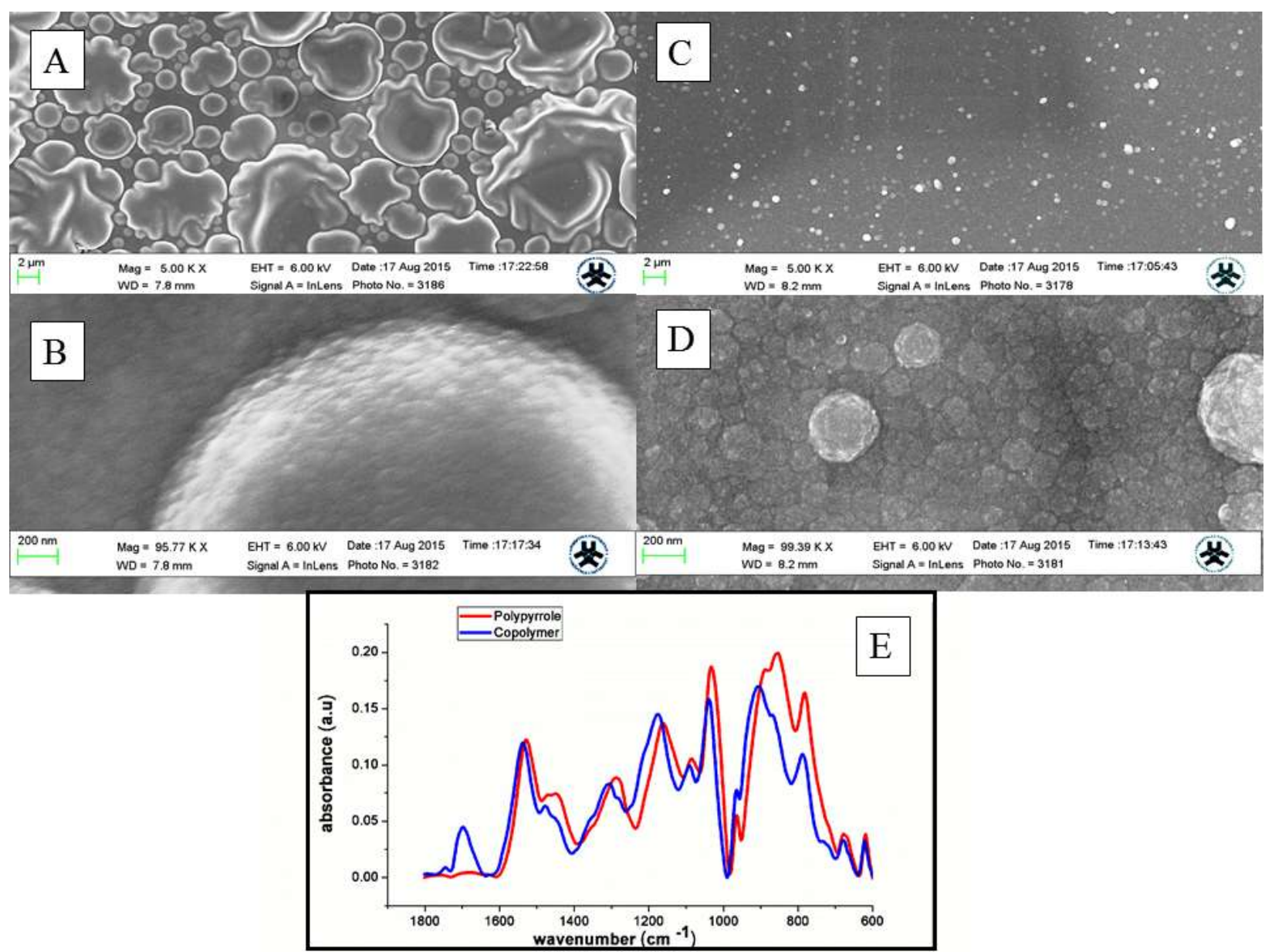

508

509

510

Figure 1

511 


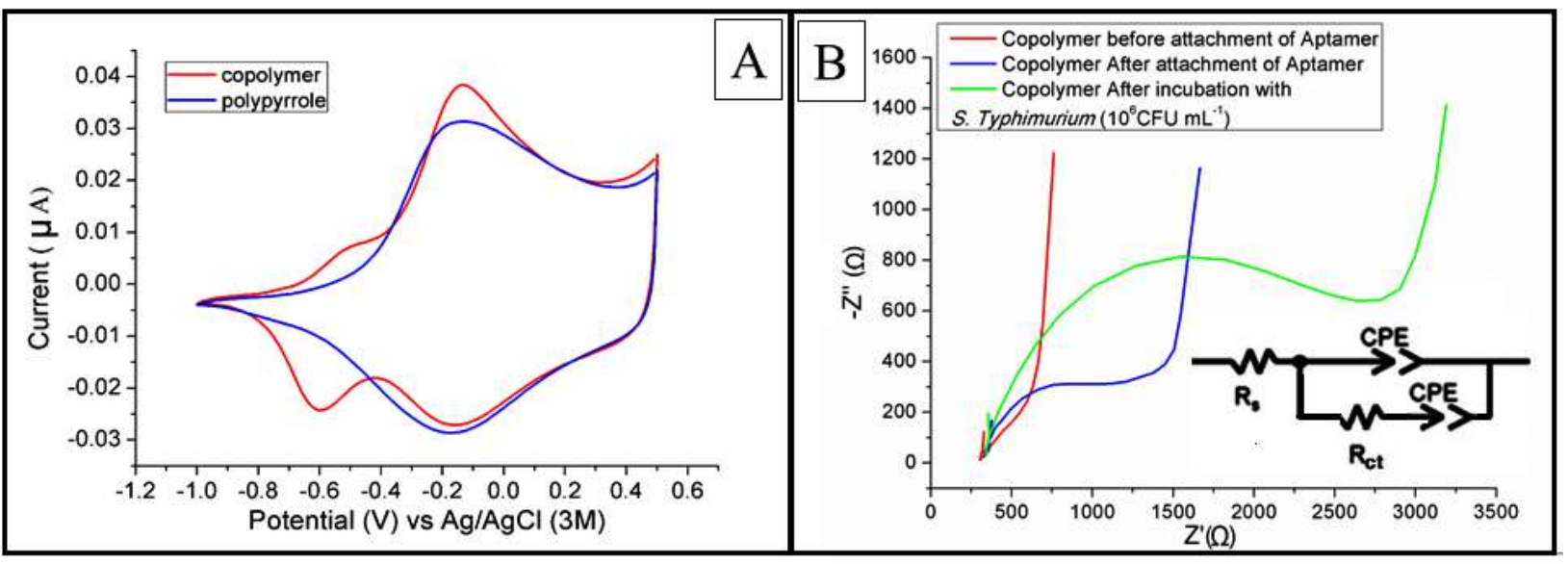

514

Figure 2

516

517 

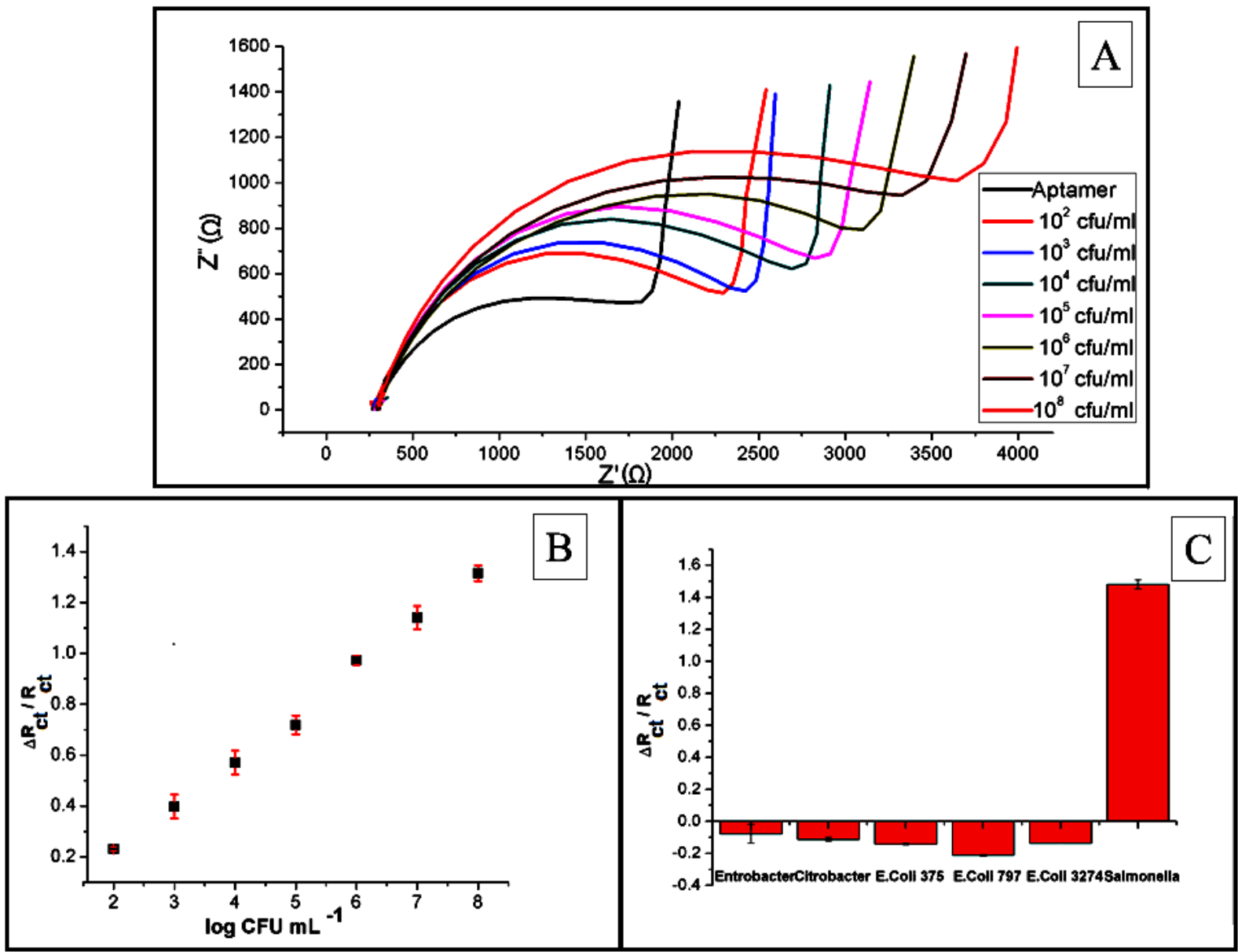

522 